\title{
Presidente ou presidenta? Com a palavra os senadores e as senadoras da República Federativa do Brasil
}

\section{Presidente or presidenta? With the word the senators of the Federative Republic of Brazil ${ }^{1}$}

\section{Cássio Florêncio Rubio}

Universidade da Integração Internacional da Lusofonia Afro-Brasileira, Redenção,

Ceará/Brasil

cassiorubio@unilab.edu.br

Fábio Fernandes Torres

Universidade da Integração Internacional da Lusofonia Afro-Brasileira, Redenção,

Ceará/Brasil

fabioftorres@unilab.edu.br

Resumo: Este artigo tem o objetivo de apresentar estudo sociolinguístico sobre a alternância das formas lexicais presidente e presidenta no contexto político específico do interrogatório da presidente/presidenta Dilma Rousseff no processo de impeachment. O corpus é composto de amostras de fala de 48 senadores e senadoras brasileiros que interpelaram diretamente a acusada. Como referencial teórico-metodológico, consideramos os pressupostos da Sociolinguística Quantitativa Laboviana (LABOV, 1972, 1990, 1994, 2008; WEINREICH, LABOV, HERZOG, 2006). Foram considerados, na análise da alternância lexical, os fatores extralinguísticos: sexo, escolaridade, faixa etária, partido político, voto e posicionamento em tribuna a respeito do processo de impeachment; e os fatores linguísticos: contexto anterior e função da forma lexical na sentença. Os resultados revelaram que a escolha de uma forma em

\footnotetext{
${ }^{1} \mathrm{Na}$ tradução para o inglês, opta-se por manter os termos presidente e presidenta em português, tendo em vista a ausência de morfema flexional de gênero nessa língua.
} 
detrimento de outra, no contexto de uso analisado, é influenciada pelos seguintes fatores extralinguísticos: partido político, voto no processo, posicionamento em tribuna e sexo.

Palavras-chave: presidente; presidenta; impeachment; variação lexical; sociolinguística quantitativa.

Abstract: This paper aims to present a sociolinguistic study about the alternation of the lexical forms presidente and presidenta in the specific political context of the interrogation of the president Dilma Rousseff in her impeachment process. The corpus is composed of 48 Brazilian senators pronunciations, who directly questioned the accused. As theoretical-methodological support, we consider the assumptions of the Labovian Quantitative Sociolinguistics (LABOV, 1972, 1990, 1994, 2008, WEINREICH, LABOV, HERZOG, 2006). In the lexical alternation analysis, we considered the following extralinguistic factors: gender, educational level, age, political party, vote and positioning in the tribune on the impeachment process; and the linguistic factors: previous context and function of the lexical form in the sentence. The results pointed out that the choice of one form over another, in the context of the analyzed use, is influenced by the following extralinguistic factors: political party, vote in the process, positioning in tribune and sex.

Keywords: presidente; presidenta; impeachment; lexical variation; quantitative sociolinguistics.

Recebido em 29 de novembro de 2016.

Aceito em 10 de abril de 2017.

\section{Introdução}

A discussão sobre o emprego das formas lexicais presidente/ presidenta ganhou maior notoriedade a partir do ano de 2010, quando, pela primeira vez na história do Brasil, uma mulher candidatou-se ao cargo máximo do Palácio do Planalto. Entretanto, a discussão tornou-se ainda mais intensa ao final do processo eleitoral, com a vitória de Dilma Rousseff para a Presidência da República e com o posicionamento explícito da recém-eleita em favor do uso da forma lexical presidenta para sua referência, em detrimento da forma presidente, empregada até aquele momento para todos os homens que haviam ocupado o mesmo cargo. 
Passada a eleição da presidente/presidenta ${ }^{2}$ da república Dilma Rousseff, não houve, até o momento, consenso sobre o emprego de uma ou outra forma, ou, ainda, sobre a possível aceitação das duas formas como mais um processo de variação do português brasileiro. Longe de caminhar para seu final, a discussão ressurge a cada novo posicionamento de figuras públicas na mídia, independentemente da forma empregada.

O presente artigo não tem a pretensão de encerrar a controversa discussão, mas, sim, buscar, em primeiro lugar, a comprovação do processo de variação entre as duas formas (presidentelpresidenta) na fala dos senadores e senadoras brasileiros e, em segundo lugar, apresentar os fatores que influenciam esse processo, destacando a sua natureza linguística ou extralinguística, no contexto específico do cenário político brasileiro.

Antecede a discussão dos resultados da pesquisa, breve revisão bibliográfica da temática em gramática normativa e prescritiva, manual de morfologia, dicionário, vocabulário ortográfico da língua portuguesa e textos recentes que circulam na mídia eletrônica. Optamos por não fazer uma separação formal do tópico entre as diferentes abordagens, haja vista serem maiores as convergências do que as divergências entre elas no material consultado, de modo que a organização, portanto, está pautada na revisão da temática, partindo-se de conteúdo mais amplo para mais específico.

\section{0 gênero em língua portuguesa}

Na língua portuguesa, os substantivos estão divididos em dois gêneros: o masculino e o feminino. A definição, segundo Bechara (2001), dá-se pela possibilidade de anteposição do artigo $o$, no caso do masculino, como em o sol, o homem, o pente, o filho; e do artigo $a$, no caso do feminino, como em a lua, a ponte, a filha, a mulher.

Para Câmara Jr. (1984), a natureza semântica dos gêneros é pouco compreendida e, normalmente, associada ao sexo dos seres. A realidade, porém, é que o gênero distribui-se em classes mórficas, nos nomes, como as conjugações se distribuem nos verbos, com a diferença de que, nesses últimos, não há implicação semântica. Perini (2010) afirma que a designação de gênero é característica de todos os nominais

\footnotetext{
${ }^{2}$ Opta-se, ao longo de todo o texto, nas referências relacionadas à presidente/presidenta Dilma Rousseff, pela menção das duas formas.
} 
que apresentam potencial referencial, ou seja, o gênero, sem qualquer exceção, é inerente ao nominal referencial.

Segundo Souza-e-Silva e Koch (2011), o processo de flexão de gênero realiza-se com o acréscimo do morfema flexional $-a$ ao final da forma masculina. Para as formas terminadas em vogal temática, como parente, há a supressão dessa vogal, por meio de uma mudança morfofonêmica $(\mathrm{e}+\mathrm{a}=$ parenta $)$. As morfólogas afirmam, entretanto, que nem todas as palavras recebem a flexão e que a vogal final não indica o gênero, mas, sim, a classe gramatical, como em criança, casa, cônjuge etc. Nesses casos, a marcação de gênero se dá pela anteposição do artigo (a casa, a criança, o cônjuge).

A determinação do gênero nos substantivos, acrescenta Câmara Jr. (1970), não se apresenta do mesmo modo que no adjetivo ou no pronome, por simples processo flexional, embora alguns substantivos pareçam manifestar a oposição entre os gêneros pela flexão, como em garoto/garota, prefeito/prefeita. Notadamente, o acréscimo de $-a$ (ou a permuta dele com $-o$ ), no substantivo, atualiza-o semanticamente, como em jarro/jarra (tipo especial de jarro), barco/barca (barco grande). ${ }^{3}$

Bechara (2001, p. 132) menciona ainda que, mesmo nos pares em que a atualização semântica não é tão notável, "a oposição masculino - feminino faz alusão a outros aspectos da realidade, diferentes da diversidade de sexo", como em lobo/loba (a fêmea do animal chamado lobo). Dessa forma, o masculino é a forma semanticamente não marcada, ${ }^{4}$ geral, e o feminino expressa uma especialização de determinada natureza.

\footnotetext{
${ }^{3}$ Os exemplos são de Câmara Jr (1984, p.79).

${ }^{4}$ Givón (1990, p. 5-6) defende que o princípio da marcação manifesta-se nas línguas naturais do seguinte modo: a categoria marcada é estruturalmente mais complexa, e a não marcada é mais simples. Esse princípio está associado, também, à frequência de uso das categorias nos diversos contextos de comunicação, de modo que as formas mais frequentes são categorias não marcadas, e as formas menos frequentes são marcadas. O princípio da marcação é desdobrado, então, em três subprincípios: a) o subprincípio da complexidade estrutural - a estrutura marcada tende a ser mais complexa (ou maior) do que a não marcada; (b) o subprincípio da distribuição de frequência - a categoria marcada tende a ser menos frequente do que a não marcada e c) o subprincípio da complexidade cognitiva - a categoria marcada tende a ser cognitivamente mais complexa no sentido de demandar maior atenção, maior esforço mental e maior tempo para seu processamento do que a categoria não marcada. Aplicando-se o princípio givoniano da marcação, o feminino é a categoria marcada em língua portuguesa, e o masculino é a não marcada.
} 
Essas considerações justificam o fato de o gênero, em alguns substantivos, manifestar-se pela adição de um sufixo nominal, como em galo/galinha, ator/atriz; ou pelo uso de palavras diferentes, como em homem/mulher, boi/vaca, cão/cadela. Não obstante, a distinção entre os gêneros em português, assim como em outras línguas naturais, não segue tão somente questões lógicas ou biológicas, mas é fruto da norma e do próprio uso, que fica evidente quando duas ou mais línguas diferentes são comparadas, ou quando se opõem estágios diferentes da mesma língua (CÂMARA JR, 1970, p. 133-134). São exemplos os vocábulos sol e lua nas línguas portuguesa e alemã - sol (masculino) = die Sonne (feminino), lua (feminino) $=\operatorname{der}$ Mond (masculino) (BECHARA, 2001, p. 133). Isso também se verifica entre os seres animados, com os chamados substantivos epicenos, como a cobra, o tatu, o jacaré, a baleia, o tubarão; e com os substantivos comuns de dois gêneros, que são diferenciados pelo artigo ou por outros adjuntos que os acompanham, como o/a estudante, o/a depoente.

O gênero gramatical, complementa Perini (2010, p. 281), não está relacionado diretamente com o sexo, sendo possível fazer referência a um indivíduo do sexo masculino por meio de vocábulos do gênero gramatical feminino, como em a pessoa, a vítima, a criança; ou a um indivíduo do sexo feminino com vocábulos do gênero gramatical masculino, como em o cônjuge, o personagem. Destaca, ainda, o gramático descritivo, ser "inegável que existe uma tendência a correlacionar gênero e sexo nos nominais que designam pessoas e certos animais", ainda que esse fato não apresente relevância na gramática, que pode apresentar nominais de gênero feminino, como pessoa, que designa seres do sexo masculino e feminino, exícara, que não designa macho ou fêmea de nenhuma espécie.

Souza-e-Silva e Koch (2011) propõem a divisão dos gêneros com base nas formas feminina e masculina do artigo, considerando três grupos de substantivos: os de dois gêneros, com flexão redundante (o mestre/a mestra, o pintor/a pintora); os de dois gêneros sem flexão aparente (o/a camarada, o/a selvagem, o/a mártir); os de gênero único (a pessoa, a testemunha, o algoz, a mosca, a mesa, o disco, o livro, o homem, a mulher, o príncipe, a princesa, o sacerdote, a sacerdotisa).

Especificamente em relação às profissões femininas, Bechara (2001, p. 134) afirma que a presença mais acentuada de mulheres em atividades profissionais antes ocupadas exclusivamente ou quase exclusivamente por homens "tem exigido que as línguas - não só o 
português - adaptem o seu sistema gramatical a essas novas realidades". Exemplos como mestra, professora, médica, advogada, psicóloga, filósofa e juiza ilustrariam essa mudança. Além dessas formas, mais amplamente aceitas, o gramático ainda destaca as distinções entre algumas outras formas, como embaixadora (senhora que dirige a embaixada) e embaixatriz (esposa do embaixador); senadora (representante do sexo feminino no parlamento) e senatriz (esposa do senador).

Para Souza-e-Silva e Koch (2011, p. 69), como em qualquer outra descrição linguística, na descrição do gênero, é importante haver a delimitação do plano gramatical e do plano lexical, já que a gramática trata apenas dos fatos gerais da língua, cabendo ao léxico tratar dos fatos especiais. Dessa forma, somente com o auxílio de um dicionário é que se poderia completar as regras lexicais gerais, por meio da consideração de cada uma das "propriedades idiossincráticas" de cada um dos itens lexicais. Conforme assinalam as autoras: "Caberia, então, a um dicionário do Português registrar as ocorrências de gênero não explicáveis pelos padrões gerais da gramática".

Considerado o panorama sobre a flexão de gênero do substantivo em língua portuguesa, passemos a tratar, na sequência, especificamente, das formas lexicais alternantes presidente/presidenta.

\section{Presidente $x$ presidenta}

Nos dicionários, o substantivo feminino presidenta tem seu primeiro registro datado do ano de 1925, na segunda edição de Caldas Aulete e na quarta edição de Cândido de Figueiredo, conforme registra pesquisa lexicográfica de Ferreira e Silva (2011), divulgada em meio eletrônico. A origem do termo, afirmam as lexicógrafas, está relacionada ao vocábulo presidente, advindo do latim praesidens, entis, particípio presente do verbo latino praesidere (estar sentado diante; vigiar, proteger, governar, presidir), por derivação. A substituição da vogal temática (-e) pela desinência do feminino $(-a)$ se deu por analogia a inúmeras outras formas como chefa, governanta e infanta (esta última registrada na língua desde o século XVIII).

São muitos os registros de palavras que, independentemente da forma mais antiga, com a vogal temática $-e$, comum de dois gêneros, ganharam, com a substituição de $-e$ pelo morfema $-a$, uma nova forma específica para o feminino, como mestra, hóspeda, monja e giganta (todas registradas em FERREIRA, 2009, p. 981, 1059, 1318, 1352). 
Além do registro das formas femininas citadas, Ferreira (2009, p. 1626) apresenta também a forma lexical presidenta, juntamente com a forma mais antiga, presidente, como segue:

Presidenta. [Fem. de presidente.] S. f. 1. Mulher que preside. 2. Mulher de um presidente.

Presidente. [Do lat. Presidente.] S. 2 g. 1. Pessoa que preside. 2. Pessoa que dirige os trabalhos duma assembleia ou corporação deliberativa. S. m. 3. O presidente da República. Adj. 2. g. 4. Bras. Ant. Governador de Estado. Presidente da República. Chefe de Estado republicano.

Cabe destaque o registro, nas duas acepções da forma presidenta, da palavra mulher, restringindo seu uso ao sexo feminino, diferentemente do que se registra na forma presidente, que apresenta, nas duas primeiras definições, a palavra pessoa, que amplia seu emprego para ambos os sexos. A terceira acepção da forma presidente, contudo, específica para o cargo de presidência da república, apresenta-se delimitada ao sexo masculino pelo emprego do artigo $o$.

$\mathrm{O}$ registro de ambas as formas não se restringe aos dicionários. Em publicação do Vocabulário ortográfico da língua portuguesa (VOLP) de 2008, organizado pela Academia Brasileira de Letras (ABL), as formas presidenta e presidente encontram-se presentes: "presidenta s. f.; presidente adj. s.2.g. s.m." (p. 674). ${ }^{5}$

Independentemente dos comprovados registros das duas formas nos dicionários e vocabulários ortográficos e também da confirmação da forma presidenta como "correta" ou "aceita" por parte de inúmeros gramáticos normativos e lexicógrafos, a discussão permanece presente no âmbito nacional, ganhando, ao longo desses anos, novos contornos, direcionados predominantemente por fatores extralinguísticos (questões notadamente relacionadas à ideologia e à política).

Ainda que não seja objetivo central deste trabalho, de cunho predominantemente sociolinguístico, propor ampla discussão de caráter político ou ideológico, procederemos à brevíssima exposição de posicionamentos relacionados ao emprego das formas variantes presidente e presidenta por figuras públicas em veículos midiáticos.

\footnotetext{
${ }^{5}$ Vocabulário ortográfico da língua portuguesa, Academia Brasileira de Letras, 5. ed. - São Paulo: Global, 2009 (finalizada em 2008).
} 
Em texto publicado originalmente pelo Diário da Manhã, no final de 2010, ${ }^{6}$ o ex-presidente da República e membro da ABL, José Sarney, defende que o dilema envolve "semântica e política", alertando que, do ponto de vista normativo, ambas as formas seriam "corretas". No mesmo texto, Sarney apresenta a opção de alguns veículos da imprensa, como a Folha de S. Paulo, pela forma presidente, independentemente da escolha da recém-eleita.

Em seu breve texto, Sarney já anunciava quais seriam os caminhos engendrados pela discussão, que, a princípio, parecia pertencer à lexicografia e a ramos de estudo da linguagem ligados à linguística histórica e ao emprego normativo da língua. Ressaltou o autor do texto e ex-presidente da República que as "escolhas" dos meios de comunicação, dos políticos ligados ou contrários ao governo e da própria presidente/ presidenta, certamente, levariam sempre em conta "o aspecto político".

Ao longo dos mais de seis anos que se passaram desde a primeira candidatura de Dilma Rousseff à Presidência do Brasil, conforme previa Sarney, muitos foram os textos que trataram da questão, com diferentes vieses, ora mais ligados ao emprego da norma padrão, ora com notável tendência à defesa de determinada ideologia. $\mathrm{O}$ fato inconteste, independentemente das intenções dos produtores dos textos, é que esses se confrontaram com ferrenhos posicionamentos, sempre permeados por conflitos político-ideológicos.

Mais recentemente, em agosto de 2016, a polêmica ganhou novos contornos, por ocasião da posse de uma mulher na presidência do Supremo Tribunal Federal (STF). Na ocasião, a ministra Carmen Lúcia Antunes Rocha recusara a forma presidenta, quando indagada pelo também Ministro do STF, Ricardo Lewandowski, sobre sua preferência entre as formas presidente/presidenta, afirmando: "Eu fui estudante e eu sou amante da língua portuguesa. Acho que o cargo é de presidente, não é não?".

O gramático normativo Pasquale Cipro Neto, em artigo publicado dias depois no periódico diário Folha de S. Paulo, com o título "Data venia, ministra Carmen Lúcia, o cargo é de 'presidente' ou de "presidenta", defendeu o emprego da forma presidenta como

${ }^{6}$ Disponível em: <http://www.academia.org.br/artigos/presidenta-ou-presidente>. Acesso em: 14 fev. 2017. 
"correto", em resposta à fala da ministra e presidente/presidenta do STF, Carmem Lúcia. ${ }^{7}$

Os posicionamentos da ministra e do gramático, políticos ou não, deram vitalidade à antiga discussão e trouxeram à tona, novamente, a polarização entre partidários favoráveis e contrários à presidente/ presidenta da república (e não à do $\mathrm{STF}$, até então, personagem central dos fatos). Muitas foram as manifestações, nos mais variados meios de comunicação; todas, incondicionalmente, comprovando a polaridade suscitada pela questão.

Considerando a contextualização sócio-histórica do fenômeno variável, a proposta deste estudo é mostrar, quantitativamente, o quanto o emprego de uma ou de outra forma, por parte dos senadores e das senadoras, sofre influência de fatores de ordem linguística e extralinguística. A nossa hipótese é de que a "opção" pelo emprego das formas em variação sofra maior influência de fatores extralinguísticos, em especial os ligados ao posicionamento político-ideológico de cada parlamentar, cuja descrição e importância serão apresentadas na seção sobre metodologia.

\section{A Sociolinguística Variacionista: alguns pressupostos}

A Sociolinguística Variacionista, também conhecida como Teoria da Variação e Mudança ou Sociolinguística Laboviana, surge a partir do trabalho de Weinreich, Labov e Herzog (1968) e das contribuições dos estudos de Labov, como uma ruptura aos modelos científicos de estudos da linguagem praticados até então - o estruturalismo e o formalismo. Os autores propuseram uma teoria da mudança linguística que pudesse descrever a língua e seus fatores determinantes, sejam de ordem linguística ou social, repelindo a noção de sistema homogêneo, para conceber a língua como um sistema dinâmico, heterogêneo, sensível a mudanças provocadas por fatores de ordem linguística e social, que deve ser estudado com base em dados reais de uma comunidade de fala.

Segundo Camacho (2009, p.147), a ruptura mais saliente promovida pela Sociolinguística é, sem dúvidas, a nova abordagem dos

\footnotetext{
${ }^{7}$ Disponível em: <http://www1.folha.uol.com.br/colunas/pasquale/2016/08/1804215data-venia-ministra-carmen-lucia-o-cargo-e-de-presidente-ou-presidenta.shtml $>$. Publicado em 18 ago. 2016. Acesso em 22 set. 2016.
} 
fenômenos variáveis, tratados nos modelos anteriores como sujeitos à variação livre - concepção de que a alternância entre as formas disponíveis na língua estaria submetida ao livre arbítrio do falante ou à seleção facultativa - conceito apropriado ao modelo de língua homogênea, mas que não se sustenta diante da observação empírica de uma língua em uso. A noção de variação livre dá lugar ao conceito de regra variável, no modelo proposto por Labov (1978, p. 2), isto é, dois enunciados que se referem ao mesmo estado de coisas, com o mesmo valor de verdade, constituem-se como variantes de uma mesma variável (regra variável).

Os trabalhos pioneiros de Labov (1972) tinham como foco fenômenos variáveis de natureza fonológica, cujo objetivo era provar que a escolha de uma variante em detrimento de outra era motivada por fatores sociais ou estilísticos. Os resultados encontrados encorajaram pesquisas em outros níveis linguísticos, como o trabalho de Weiner e Labov (1977) sobre a alternância entre as estruturas ativa e passiva sem agente do inglês, isto é, os autores trataram essas construções como variantes linguísticas e estenderam a regra variável ao nível sintático. Esse fato desencadeou uma interessante discussão entre Lavandera (1978) e Labov (1978).

Lavandera (1978) questionou se seria apropriado estender a noção de regra variável a outros níveis de análise, como o sintático, por exemplo, visto que as construções sintáticas têm traços de significado próprios. Em resposta a Lavandera, Labov (1978, p. 2) argumenta que a noção de significado referencial, também chamado de significado representacional ou estado de coisas, sustenta-se sob a alegação de que "dois enunciados que se referem ao mesmo estado de coisas têm o mesmo valor de verdade" (tradução nossa). ${ }^{8}$ Em vez de alargar a noção de significado referencial, Labov (1978, p. 2-3) delimita-o ainda mais ao afirmar que só percebemos que alguém fala como um homem do campo porque existem formas rurais e formas urbanas com o mesmo significado; só sabemos que alguém nos tratou de modo polido porque sabemos que esse alguém escolheu uma das várias maneiras de dizer a mesma coisa.

No caso desta pesquisa, que lida com a variação lexical das formas presidente e presidenta, poder-se-ia questionar, segundo a lógica de Lavandera (1978), se seria adequado o tratamento variacionista para

\footnotetext{
${ }^{8}$ [I would like to say that] two utterances that refer to the same state of affairs have the same truth-value.
} 
explicar a escolha entre uma forma e outra. Novamente, apoiamo-nos no próprio Labov (1978, p.5), ao afirmar que o primeiro passo é reconhecer que o procedimento técnico básico para uma análise variacionista começa com o isolamento e a definição dos termos que variam, isto é, os termos devem se referir ao mesmo estado de coisas e, por consequência, devem possibilitar a alternância de um pelo outro sem que se altere o seu valor de verdade. Nosso foco é a variação lexical entre as formas presidente e presidenta, que têm como referente biossocial a presidente/presidenta Dilma Rousseff, nos discursos proferidos pelos senadores e senadoras, durante seu julgamento de impeachment, isto é, trata-se do mesmo referente, do mesmo significado referencial, do mesmo estado de coisa. $\mathrm{O}$ uso da forma presidente, que tenha como referente biossocial um sujeito do sexo masculino, não admite variação, por razões inerentes ao próprio sistema linguístico da língua portuguesa.

As formas presidente e presidenta são formas que se alternam e que exercem a mesma função sintática no contexto de investigação. Como discutido por Paiva; Scherre (1999) e Freitag (2009), entre outros, longe de se constituir empecilho, a consideração de outros fenômenos, que não os de nível fonológico, promove um alargamento do escopo da sociolinguística e a proposição de novas interfaces com outras teorias linguísticas, que proporcionam visão mais ampla dos fenômenos linguísticos, como propomos neste trabalho.

Segundo Labov (2008, p. 16), a grande revelação a que se propõe a sociolinguística é conceber a mudança linguística como racional e, desse modo, possibilitar a descrição e a diferenciação das formas de determinada língua em uma comunidade. O domínio de estruturas heterogêneas, longe de ser considerado multidialetalismo, é "parte da competência linguística monolíngue". As possíveis explicações sobre a variação e mudança linguística envolveriam três questões distintas: a origem das variações, a difusão e a propagação e a regularidade da mudança linguística.

Para isso, é importante considerar o contexto social (no caso desta pesquisa, o político) em que o fenômeno variável ocorre. Cabe observar, também, o significado ou valor social de cada uma das formas variantes, já que é comum haver a observação da polaridade entre norma e uso na investigação de fenômenos variáveis das línguas naturais. Essas ponderações vão ao encontro do que propõe Eckert (1996), ao defender que os estudos de variação se centram nas comunidades de prática, locus 
compartilhado pelos indivíduos em torno de uma meta comum, o que relaciona crenças, valores e objetivos específicos do grupo. Há, com base nessa perspectiva, uma relação íntima entre a língua e a identidade do falante, ou seja, os estilos de cada indivíduo e as marcas de identidade social ganham destaque no estudo da variação linguística.

\section{Metodologia}

O corpus utilizado para a análise se compõe das gravações das falas de 48 senadores da república durante a sessão de interrogatório da presidente/presidenta Dilma Rousseff, realizada no dia 29 de agosto de 2016. ${ }^{9,10}$ Foram considerados aproximadamente 250 minutos, referentes ao tempo de pronunciamento de cada um dos senadores que fizeram uso da palavra na sessão. A fala de resposta da presidente/presidenta não foi considerada na pesquisa. As intervenções do presidente da sessão, ministro do Supremo Tribunal Federal - STF, Ricardo Lewandowski, ${ }^{11}$ foram computadas, entretanto os resultados serão apresentados separadamente, em razão da não aplicabilidade de alguns dos fatores extralinguísticos considerados na pesquisa, como voto, partido político e posição no processo.

Foram analisadas todas as menções orais das formas alternantes presidente (conforme ocorrências (1), (2)) e presidenta (conforme ocorrências (3) e (4)), por parte dos senadores e das senadoras, que apresentavam como referente a interrogada na sessão, presidente/ presidenta Dilma Rousseff, constituindo-se estas as variantes da variável dependente. ${ }^{12}$ Consideramos a forma presidente uma variante

\footnotetext{
${ }^{9}$ As gravações foram baixadas do site oficial da TV Senado, http://www.senado.leg. br/noticias/tv/, com Acesso em 1 de set. 2016.

${ }^{10}$ As transcrições de toda a sessão do processo de impeachment se encontram disponíveis no site do Senado, no link https://www25.senado.leg.br/web/atividade/ notas-taquigraficas/-/notas/s/3885. Acesso em 10 de out. 2016.

11 Para informação, o ministro Ricardo Lewandowski, ao se referir à presidente/ presidenta Dilma Rousseff, empregou 81 vezes $(79,4 \%)$ a forma presidente e 21 vezes $(20,6 \%)$ a forma presidenta.

${ }^{12}$ As ocorrências da forma presidente para outros referentes, como o ministro do Supremo Tribunal Federal, Ricardo Lewandowski, o senador Renan Calheiros e o presidente interino Michel Temer não foram consideradas na rodada geral de dados. $\mathrm{Na}$ apresentação da ocorrência, aparece o nome do senador seguido do partido político e do estado que representa.
} 
“conservadora", já que tem origem mais antiga na língua, e presidenta, uma forma "inovadora" por ser de uso mais recente.

(1) ...o seu compromisso com a solução de tudo o que tive a chance de lhe apresentar foram definitivos para que eu tivesse a certeza absoluta que a senhora é a presidente que mais atenção deu ao agronegócio brasileiro nas últimas três décadas...

(Senadora Kátia Abreu, PMDB, TO)

(2) e pra formar juízo é preciso compreender os fatos e conhecer os argumentos de quem é acusado da sua prática... vossa excelência... senhora presidente tem formação de economista... eu sou administrador de empresas e contador...

(Senador Paulo Bauer, PSDB, SP)

(3) senhor presidente Lewandowski... senhora presidenta Dilma Roussef... eu queria fazer uma saudação aqui ao ex-presidente Lula que esteve conosco há pouco tempo... pelo legado que deixou a esse país...

(Senadora Gleisi Hoffmann, PT, PR)

(4) presidente Lewandowski... presidenta eleita... do Brasil... Dilma Vana Rousseff... antes de ontem eu estava num comício no turvo... centro do Paraná... região pobre de agricultores que vivem em extrema dificuldade...

(Senador Roberto Requião, PMDB, PR)

Os grupos de fatores considerados são os seguintes: escolaridade, faixa etária, sexo, partido político, voto e posicionamento em tribuna a respeito do processo de afastamento (extralinguísticos); contexto anterior e função do SN que contém a forma lexical na sentença (linguísticos). A seguir, encontram-se a apresentação e a justificativa de investigação de cada um dos grupos:

\subsection{Fatores extralinguísticos}

\subsubsection{Escolaridade: ensino médio e ensino superior}

Concernente ao grupo de fatores escolaridade, a estratificação possível, proposta com base no perfil social dos 48 parlamentares que tiveram sua fala analisada, apresenta as escolaridades ensino médio completo e ensino superior. Não há, contudo, equivalência entre os dois estratos, haja vista 41 terem nível de escolarização superior e 7, nível de escolarização médio ou equivalente. Foram considerados (as) também no 
grupo ensino superior os(as) senadores(as) que tinham, além do ensino superior, pós-graduação.

A hipótese clássica para a atuação do grupo de fatores escolaridade em estudos sociolinguísticos relaciona-se, normalmente, à maior frequência de emprego da forma padrão por parte dos mais escolarizados (v., entre outros, VOTRE, 2015). Entretanto, para o fenômeno considerado, as duas formas são registradas como padrão em dicionários e no Vocabulário Ortográfico Oficial da Língua Portuguesa.

\subsubsection{Faixa etária: 40 a 50 anos, 50 a 60 anos, 60 a 70 anos, mais de 70 anos}

O grupo faixa etária também foi proposto com base no perfil social da amostra, que contava com seis parlamentares com idade entre 40 e 49 anos, 19 com idade entre 50 e 59 anos, 13 com idade entre 60 e 69 anos, e 10 com idade igual ou superior a 70 anos.

A hipótese para esse grupo, a considerar os inúmeros estudos do português brasileiro (ver MOLLICA, 2015, entre outros), é de que os mais idosos empreguem a forma conservadora, e os mais jovens prefiram a forma inovadora no fenômeno variável.

\subsubsection{Sexo: masculino e feminino}

Para o grupo de fatores sexo, a estratificação se deu da seguinte forma: 38 homens e 10 mulheres. A tendência para esse grupo de fatores, destacada por Fisher (1958), Labov (1990), Paiva (2015), entre outros, é a de as mulheres demonstrarem maior preferência pelas variantes mais prestigiadas socialmente, independentemente de serem formas conservadoras ou inovadoras.

Apesar da impossibilidade de se verificar o grau de estigma ou de prestígio do vocábulo inovador presidenta, é possível se identificar diferentes avaliações sobre a forma, a depender dos micronúcleos de seu uso, correlacionados a questões político-partidárias. Se para a forma presidente, a princípio, não se verifica estigma, também não é possível determinar, pela análise prévia dos discursos, o status do termo presidenta. Entretanto por esta ser a forma inovadora, a hipótese que se levanta é a de que ela seria a forma socialmente estigmatizada.

Merecem comentário as restrições da amostra em relação ao equilíbrio de perfis para fatores sociais como escolaridade, idade e sexo. Essas limitações, todavia, longe de minimizar a importância do presente 
estudo, inédito até então, ou de inviabilizar a análise, apenas revelam o cuidado no trato dos resultados e a necessidade de proceder a cruzamentos específicos que possam fornecer detalhes relacionados a cada estrato.

Para os grupos de fatores extralinguísticos "tradicionais" considerados na pesquisa (escolaridade, faixa etária e sexo), ainda que tenhamos procedido à apresentação das hipóteses clássicas, cabe destacar o contexto específico de investigação do fenômeno variável, no qual outros fatores extralinguísticos podem se mostrar, por vezes, mais atuantes. É importante considerar a natureza política da sessão na qual foram colhidas as amostras e, mais do que isso, analisar não somente o perfil social individual dos/as senadores/as, mas também seu posicionamento político-ideológico.

Especificamente em relação ao sexo do falante, merece destaque o fato de o fenômeno investigado estar fortemente correlacionado ao reconhecimento ou não da identidade de gênero da referente no discurso. Além da hipótese apresentada anteriormente, que demonstra maior sensibilidade feminina ao status social das variantes linguísticas, cabe verificar também se as mulheres seriam mais sensíveis à determinação e ao reconhecimento da identidade de gênero no discurso, haja vista, no contexto de variação investigado, apresentarem-se variantes com características identitárias ímpares, uma forma empregada indistintamente para os dois gêneros (presidente) e outra forma específica para o gênero feminino (presidenta).

Cabe diferenciar, de forma simplificada, os termos sexo e gênero, empregados ao longo desse trabalho. Sexo está relacionado às características biológicas do informante, enquanto gênero relaciona-se mais diretamente ao comportamento social do indivíduo. Dessa forma, na estratificação das amostras, procedemos ao emprego do termo sexo, o que não exclui o emprego do vocábulo gênero em nossas discussões.

Os grupos de fatores extralinguísticos que seguem não esgotam as possibilidades de medição dessa influência político-ideológica sobre a alternância lexical presidente/presidenta, mas possibilitam, minimamente, lançar um olhar objetivo e científico sobre o fenômeno. 


\subsubsection{Voto no processo de afastamento: sim ou não}

Entre os 48 parlamentares que fizeram uso da tribuna do Senado, no interrogatório da presidente/presidenta Dilma Rousseff, 29 manifestaram voto favorável ao impeachment, e 19, voto desfavorável. A consideração desse grupo de fatores tem o objetivo de investigar se o posicionamento do(a) senador(a) em relação ao afastamento influenciaria o uso efetivo de uma das formas. A hipótese, com base nas observações preliminares da amostra, é a de que os senadores com voto favorável ao impeachment tenham maior tendência ao emprego da forma presidente, enquanto os que manifestaram voto contrário empregariam com maior frequência a forma presidenta.

\subsubsection{Posicionamento a respeito do processo: golpe ou impeachment (afastamento)}

O posicionamento a respeito do processo, bastante discutido durante todas as etapas da votação na Câmara dos Deputados e do Senado, também foi considerado na investigação do fenômeno variável. Alguns dos opositores do processo denominavam-no "golpe", enquanto alguns dos políticos favoráveis o nomeavam "impeachment" ou "afastamento". Com base nessas observações, propomos o grupo posicionamento em tribuna a respeito do processo, considerando a menção explícita - por parte do(a) senador(a), em tribuna - da forma lexical "golpe" ou das formas lexicais "impeachment/afastamento". Dos(as) 48 parlamentares que fizeram uso da tribuna, 15 mencionaram as palavras "impeachment" ou "afastamento", e 9 mencionaram a forma lexical "golpe". A hipótese para esse grupo é a de que os indivíduos que empregaram as formas "impeachment" / "afastamento" demonstrem preferência pela forma presidente; por outro lado, os que mencionaram explicitamente o vocábulo "golpe" tenderiam mais ao emprego da forma presidenta. ${ }^{13}$

\footnotetext{
${ }^{13}$ Nenhum(a) dos(as) senadores(as) empregou no seu discurso as formas impeachment/ afastamento e golpe. 24 parlamentares, em seu pronunciamento em tribuna, não mencionaram as formas analisadas.
} 


\subsubsection{Partido político: PMDB, PP, PSDB, PSD, PDT, DEM, PSB, PR, PC do B, PSC, PT, PV, SEM PARTIDO, REDE, PPS, PTB ${ }^{14}$}

Esse grupo foi investigado com base em análise preliminar da amostra que apontou possível relação entre o partido político do falante e o emprego de uma ou outra forma lexical. A hipótese que carece de confirmação é a de que representantes de partidos políticos ligados ao governo da presidente/presidenta Dilma Rousseff apresentariam maior tendência de emprego da forma presidenta; por outro lado, partidos de oposição tenderiam ao emprego da forma presidente. É importante destacar a falta de objetividade na determinação da então base aliada do governo e também da oposição. Apenas alguns partidos, como PT e PSDB, podem ser considerados categoricamente como de situação e de oposição, respectivamente. A expectativa é de que a análise desse grupo forneça subsídios para apresentar, com base nos resultados estatísticos do fenômeno de alternância lexical presidente/presidenta, um contínuo entre favoráveis e opositores ao governo da então presidente/presidenta Dilma Rousseff.

\subsection{Fatores Linguísticos}

\subsubsection{Contexto anterior: sem contexto anterior, forma lexical do gênero feminino, forma lexical comum de dois gêneros}

$\mathrm{Na}$ consideração do grupo de fatores contexto anterior, a investigação recai sobre a forma lexical que antecede as variantes presidente/presidenta dentro do SN. A observação preliminar dos dados possibilitou verificar que diferentes formas poderiam anteceder o

\footnotetext{
${ }^{14}$ As siglas dos partidos referem-se às seguintes denominações: Partido do Movimento Democrático Brasileiro-PMDB; Partido Progressista - PP; Partido da Social Democracia Brasileira - PSDB; Partido Social Democrático - PSD; Partido Democrático Trabalhista - PDT; Democratas - DEM; Partido Socialista Brasileiro - PSB;Partido da República - PR; Partido Comunista do Brasil - PC do B; Partido Social Cristão - PSC; Partido dos Trabalhadores - PT; Partido Verde - PV; SEM PARTIDO (refere-se a parlamentar que não integra nenhum partido naquele momento); Rede Sustentabilidade -REDE; Partido Popular Socialista - PPS; Partido Trabalhista Brasileiro - PTB. A título de informação, ao iniciar seu segundo mandato, em 2014, a então presidente/presidenta Dilma Rousseff dispunha do apoio dos seguintes partidos que compunham a base aliada ao governo: PCB, PDT, PMDB, PP,PR, PRB, PT, PTB.
} 
vocábulo em variação, e a hipótese a ser investigada é a de que o contexto anterior influenciaria no emprego de uma ou outra forma variante.

A hipótese para esse grupo está relacionada ao "princípio do paralelismo formal", amplamente investigado em estudos de concordância verbal e nominal do português brasileiro, que mostram que as marcas tendem a se repetir em estruturas subsequentes ao longo da sentença ("marcas levam a marcas") (SCHERRE, 1998, p. 30 et seq.). Com base nesse princípio, a expectativa é de que as ocorrências que apresentam contexto anterior com forma lexical feminina (ocorrência (6)) favoreçam o emprego de presidenta e, por outro lado, as ocorrências que não apresentam contexto anterior ou que apresentam forma comum de dois gêneros no contexto prévio (ocorrências (5) e (7), respectivamente) favoreçam o emprego de presidente. Vejamos as ocorrências exemplificativas de cada contexto:

(5) queria dizer... presidente... que eu tive o privilégio de servir a senhora...

(Senador Armando Monteiro, PTB, PE)

(6) vossa excelência... senhora presidenta... é um orgulho para o país...

(Senador José Pimentel, PT, CE)

(7) Ilustre presidente Dilma Roussef...

(Senador Roberto Muniz, PP, BA)

\subsubsection{Função do SN: sujeito, vocativo, complemento verbal}

Para o grupo de fatores função do $S N$, verifica-se a função exercida pelo sintagma nominal que abriga as formas em variação presidente/presidenta na sentença. Foram observadas, nas amostras, três funções, a de sujeito (ocorrência (8)), a de vocativo (ocorrência (9)) e a de complemento verbal (ocorrência (10)). A hipótese, baseada em análise prévia da amostra e na Teoria da Polidez, proposta por Brown e Levinson (1987), a ser confirmada, é de que haja maior emprego da forma presidenta nos vocativos, haja vista, nesses casos, a referente se constituir na interlocutora direta do discurso. Entre as "estratégias de polidez" apresentadas pelos autores estão a polidez positiva (inclusão do ouvinte na atividade, simulação ou explicitação da reciprocidade, uso de marcas de identidade de grupo) e a polidez negativa (emprego convencionalmente indireto, referência impessoal ao falante e ao ouvinte, deslocamento do ouvinte). Por outro lado, os SNs em posição 
de sujeito e de complemento verbal têm como interlocutores todos os que acompanhavam a sessão do senado. A suposição é de que os parlamentares que optam pelo direcionamento direto do discurso à interrogada estariam optando por estratégias de polidez positiva, enquanto os que optam pelo direcionamento a todos os presentes, reportando-se à interrogada em terceira pessoa, estariam optando pela polidez negativa. ${ }^{15}$ Por consequência, essa "opção" se refletiria também no emprego das formas presidenta/presidente. A seguir, são apresentadas ocorrências exemplificativas.

(8) a presidente Dilma insinuou a hipótese de que por detrás dos movimentos que levaram multidões às ruas...

(Senador Álvaro Dias, PV, PR)

(9) Senhor presidente do Supremo Tribunal Federal Ricardo Lewandowski... senhora presidenta da República Dilma Rousseff... presidenta Dilma... eu venho lá do sul...

(Senador Paulo Paim, PT, RS)

(10) peço permissão para nesse exíguo lapso temporal fazer um registro sobre uma grande presidente a quem tive a honra de apoiar...

(Senador Hélio José, PMDB, DF)

As ocorrências foram codificadas e submetidas a tratamento estatístico no programa GoldvarbX, que permite uma análise multivariada dos fatores condicionadores da variação linguística, conforme Sankoff, Tagliamonte (2005). Os resultados gerais e relativos aos fatores considerados são discutidos na próxima seção.

\section{Análise dos resultados}

Foi considerado na análise um total de 232 ocorrências, entre as quais $62,5 \%$ (145) são da forma lexical presidente, e 37,5\% (87), da forma presidenta, como podemos observar na tabela 1 .

\footnotetext{
${ }^{15}$ Em relação às nuances de subjetividade e pessoalidade verificadas entre o emprego da segunda e terceira pessoas, é importante destacar Benveniste (1991), que estabelece diferença circunstancial entre o $\mathrm{eu} / \mathrm{tu}$, autênticas pessoas, categorias do discurso; e o ele, uma categoria da língua, uma não-pessoa.
} 
TABELA 1 - Resultados gerais da alternância entre as formas presidente/presidenta

\begin{tabular}{c|c}
\hline \multicolumn{2}{c}{ RESULTADO GERAL - ALTERNÂNCIA LEXICAL } \\
\hline Presidente & Presidenta \\
\hline$\%\left(\mathrm{n}^{\mathrm{o}}\right.$ de ocorrências $)$ & $\%\left(\mathrm{n}^{\circ}\right.$ de ocorrências $)$ \\
\hline $\mathbf{6 2 , 5 \%}(145 / 232)$ & $\mathbf{3 7 , 5 \%}(87 / 232)$ \\
\hline
\end{tabular}

Fonte: Elaborada pelos autores.

Os resultados gerais apresentam um processo de variação lexical, com predomínio da forma presidente sobre a forma presidenta. Concernente aos diversos fatores linguísticos e extralinguísticos abarcados, apresentamos, no quadro 1, aqueles selecionados pelo programa estatístico como relevantes no fenômeno variável.

QUADRO 1 - Ordem de seleção dos fatores na alternância lexical presidente/presidenta

\begin{tabular}{|c|c|c|}
\hline Fenômeno & Fatores & $\begin{array}{c}\text { Alternância lexical } \\
\text { presidente } x \text { presidenta }\end{array}$ \\
\hline \multirow{6}{*}{ Extralinguísticos } & Partido político & $1^{\mathrm{o}}$ \\
\hline & Voto no processo & $2^{\circ}$ \\
\hline & Posicionamento em tribuna & $3^{\circ}$ \\
\hline & Sexo & $4^{\circ}$ \\
\hline & Faixa etária & não selecionado \\
\hline & Nível de escolaridade & não selecionado \\
\hline \multirow{2}{*}{ Linguísticos } & Contexto anterior & não selecionado \\
\hline & Função do SN & não selecionado \\
\hline Goldvarb X & \multicolumn{2}{|c|}{ Log likelihood $=-55.627$ Significance $=0.007$} \\
\hline
\end{tabular}

Fonte: Elaborado pelos autores. 
Como se pode observar, somente fatores extralinguísticos foram selecionados como relevantes no fenômeno de alternância lexical entre as formas presidente/presidenta. Cabe destacar, entre os selecionados, três fatores (partido político, voto no processo e posicionamento em tribuna) mais fortemente ligados ao caráter político-ideológico do fenômeno linguístico, que é o foco desta investigação, e o último, sexo, reconhecidamente associado às discussões de gênero presentes nos debates sobre a temática.

A faixa etária e a escolaridade dos senadores e senadoras não foram consideradas relevantes na alternância lexical. Da mesma forma, os fatores linguísticos contexto anterior à forma lexical e função do SN que abriga a forma lexical também não foram selecionados pelo programa estatístico.

$\mathrm{Na}$ sequência, trataremos mais detalhadamente de cada um dos grupos considerados relevantes. ${ }^{16}$

\subsection{Partido político}

A motivação para o controle do grupo de fatores partido político é de confirmar se o emprego de uma ou outra formas lexicais (presidente) presidenta) seria influenciado pelo partido político ao qual o/a senador/a pertence. ${ }^{17}$ Seguem os resultados para esse grupo na tabela 2 .

${ }^{16}$ Optamos por rodadas que considerassem como fator de aplicação uma e outra variantes, com o intuito de proporcionar apresentação que possibilite visão mais ampla do fenômeno, em função da forma "presidente" e da forma "presidenta". Nas tabelas, exibe-se a distribuição complementar das frequências e pesos relativos.

${ }^{17}$ Faz-se necessário destacar, neste ponto, a imprecisão na determinação de partidos e de políticos de "oposição" ou "situação", "direita" ou "esquerda", "aliados" ou "contrários". 
TABELA 2 - Atuação do grupo de fatores partido político na alternância presidente/presidenta

\begin{tabular}{|c|c|c|c|}
\hline Variantes & Partido Político & $\% / n^{0}$ de ocorrências & Peso rel. \\
\hline \multirow{5}{*}{ 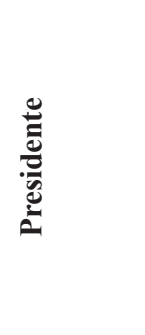 } & $\begin{array}{l}\text { PP, PSDB, PSD, DEM, PSB, PR, } \\
\text { PPS, PTB, PSC, PV, S/P, REDE }\end{array}$ & $98,1 \%(103 / 105)$ & 0,907 \\
\hline & PMDB & $83,3 \%(20 / 24)$ & 0,597 \\
\hline & PDT & $71,4 \%(10 / 14)$ & 0,313 \\
\hline & PC do B & $42,9 \%(6 / 14)$ & 0,228 \\
\hline & PT & $8 \%(6 / 75)$ & 0,050 \\
\hline \multirow{5}{*}{ 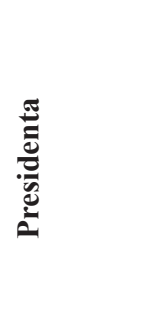 } & $\begin{array}{l}\text { PP, PSDB, PSD, DEM, PSB, PR, } \\
\text { PPS, PTB, PSC, PV, S/P, REDE }\end{array}$ & $1,9 \%(2 / 105)$ & 0,093 \\
\hline & PMDB & $16,7 \%(4 / 24)$ & 0,403 \\
\hline & PDT & $28,6 \%(4 / 14)$ & 0,687 \\
\hline & PC do B & $57,1 \%(8 / 14)$ & 0,772 \\
\hline & $\mathrm{PT}$ & $92 \%(69 / 75)$ & 0,950 \\
\hline
\end{tabular}

Fonte: Elaborada pelos autores.

Os resultados mostram um bloco de partidos, composto de PP, PSDB, PSD, DEM, PSB, PPS, PR, PTB, PSC, PV, Sem Partido e REDE, com comportamento bastante semelhante em relação à alternância entre as formas, demonstrando forte tendência ao emprego da forma presidente (frequência de $98,1 \%$ e peso relativo de 0,907). Os/As senadores/as do PMDB, apesar da considerável frequência com que empregam a forma presidente $(83,3 \%)$, diferenciam-se do bloco anterior, o que pode ser verificado também pelo peso relativo de 0,597 , que revela menor tendência do que o grupo anterior ao emprego da forma conservadora.

Representantes do PDT, embora empreguem com maior frequência a forma presidente $(71,4 \%)$, exibiram peso relativo que indica

\footnotetext{
${ }^{18}$ A considerar a grande proximidade de percentuais verificada entre os partidos PP, PPS, PSDB, PSD, DEM, PSB, PR, PTB, PSC, PV, Sem Partido e REDE, optou-se pela amalgamação de resultados dessas siglas. A estratégia possibilitou também a rodada multivariada, com a obtenção de pesos relativos (P.R.).
} 
influência positiva no emprego da forma presidenta (peso relativo de 0,687 para essa forma).

Os/As senadores/as do PC do B exibiram frequência de mais de $57,1 \%$ de emprego da forma presidenta e peso relativo de 0,772 , revelando tendência positiva ao emprego da forma inovadora. Da mesma forma, os/as representantes do PT, partido da presidente/presidenta Dilma Rousseff, como previa nossa hipótese, foram responsáveis por $92 \%$ do emprego da forma presidenta, o que resultou em peso relativo de 0,950 para emprego dessa forma.

Como se pode constatar, o grupo de fatores partido político do/a senador/a exerce influência no comportamento linguístico quanto ao emprego das formas alternantes. O bloco de partidos formado por PP, PSDB, PSD, DEM, PPS, PSB, PR, PTB, PSC, PV, Sem Partido e REDE priorizou o emprego quase categórico da forma presidente, explicitamente preterida pela presidente/presidenta da República. Em outro extremo, os/ as representantes do PT demonstraram, em seus discursos, a tendência elevada à opção pelo uso da forma preferida de Dilma Rousseff.

A análise dos outros fatores selecionados e o cruzamento entre alguns deles permitirão discussão mais ampla do fenômeno. Passemos a apresentar o próximo grupo selecionado pelo programa estatístico, voto no processo.

\subsection{Voto no processo}

O grupo de fatores voto no processo foi controlado com o intuito de confirmar ou refutar a hipótese de que senadores/as apresentariam tendência ao emprego de uma ou de outra forma a depender de seu posicionamento político em favor ou contra o processo de impeachment. Dessa forma, os contrários ao afastamento tenderiam a empregar a forma presidenta e os favoráveis tenderiam mais ao emprego da forma presidente. A princípio, o grupo voto no processo poderia estar se sobrepondo ao grupo anterior, partido político, apresentando resultados bastante semelhantes, entretanto merece destaque o fato de haver poucos partidos nos quais todos os representantes assumiam posicionamento único em relação ao processo (apenas PT e PC do B, como veremos adiante). Na sequência, os resultados para o grupo de fatores voto no processo de impeachment. 
TABELA 3 - Atuação do grupo de fatores voto no processo na alternância presidente/presidenta

\begin{tabular}{c|c|c|c}
\hline Variantes & Voto no processo & $\mathbf{\%} / \mathbf{n}^{\mathbf{0}}$ de ocorrências & Peso relativo \\
\hline \multirow{2}{*}{ Presidente } & Sim & $97,1 \%(100 / 103)$ & $\mathbf{0 , 7 7 7}$ \\
\cline { 2 - 4 } & Não & $34,9 \%(45 / 129)$ & 0,270 \\
\hline \multirow{2}{*}{ Presidenta } & Sim & $2,9 \%(3 / 103)$ & 0,223 \\
\cline { 2 - 4 } & Não & $65,1 \%(84 / 129)$ & $\mathbf{0 , 7 3 0}$ \\
\hline
\end{tabular}

Fonte: Elaborada pelos autores.

Os resultados demonstram que, entre os senadores/senadoras favoráveis ao processo de impeachment, houve emprego quase categórico da forma presidente $(97,1 \%$ e peso relativo de 0,777$)$. Por outro lado, presidenta foi a forma lexical mais empregada pelos que votaram contra o afastamento de Dilma Rousseff (65,1\% e peso relativo de 0,730 para a forma inovadora). Há de se destacar que houve, para os que votaram não ao afastamento, um processo variável, com tendência acentuada ao emprego da forma inovadora presidenta, comportamento bastante diferente dos que votaram sim, com a apresentação do emprego quase categórico da forma conservadora. Os resultados confirmam a oposição e distanciamento de frequências e pesos relativos entre o grupo de senadores que votou sim e o grupo que votou não.

Esses resultados, aliados aos resultados do grupo de fatores partido político, poderiam confirmar que o emprego de uma ou outra forma, apesar de se correlacionar com posição contrária ou favorável à então presidente/presidenta, estaria mais fortemente ligado a uma ideologia político-partidária, ou seja, o emprego mais acentuado da forma presidenta, como mostrou o grupo anterior, estaria restrito a determinado(s) partido(s) e não ao posicionamento diante do processo. A seguir, apresenta-se, na tabela 4 , o cruzamento entre o grupo partido político e voto no processo. 
TABELA 4 - Cruzamento entre os grupos de fatores partido político e voto no processo

\begin{tabular}{l|c|c|c}
\hline \multirow{4}{*}{ Voto } & \multicolumn{2}{|c}{ Partido } & \multicolumn{2}{c}{ Variantes } \\
\cline { 2 - 4 } & & Presidente & Presidenta \\
\hline \multirow{5}{*}{ Sim } & $\begin{array}{c}\text { PP, PSDB, PSD, DEM, PSB, PPS, } \\
\text { PR, PTB, PSC, PV, S/P, REDE }\end{array}$ & $98 \%(78 / 80)$ & $2 \%(2 / 80)$ \\
\cline { 2 - 4 } & PMDB & $100 \%(12 / 12)$ & $0 \%(0 / 12)$ \\
\cline { 2 - 4 } & PDT & $91 \%(10 / 11)$ & $9 \%(1 / 11)$ \\
\cline { 2 - 4 } & PC do B & - & - \\
\cline { 2 - 4 } & PT & $100 \%(25 / 25)$ & $0 \%(0 / 25)$ \\
\hline \multirow{5}{*}{ Não } & PP, PSDB, PSD, DEM, PSB, PR, PSC, PV, S/P, REDE & $67 \%(8 / 12)$ & $33 \%(4 / 12)$ \\
\cline { 2 - 4 } & PMDB & $0 \%(0 / 3)$ & $100 \%(3 / 3)$ \\
\cline { 2 - 4 } & PDT & $83 \%(6 / 14)$ & $57 \%(8 / 14)$ \\
\cline { 2 - 4 } & PC do B & & $92 \%(69 / 75)$ \\
\cline { 2 - 4 } & PT & & \\
\cline { 2 - 4 } & & & - \\
\hline
\end{tabular}

Fonte: Elaborada pelos autores.

Os resultados tornam possível afirmar que, para o bloco de partidos composto por PP, PSDB, PSD, DEM, PSB, PR, PTB, PPS, PSC, $\mathrm{PV}, \mathrm{S} / \mathrm{P}, \mathrm{REDE}$, independentemente do voto no processo de impeachment, há recusa quase categórica ao emprego da forma presidenta. Para PMDB e PDT, interfere no emprego de uma ou outra forma o voto do parlamentar, haja vista os que votaram sim tenderem ao emprego de presidente $(100 \%$ e $91 \%$, respectivamente) e os que votaram não tenderem mais ao uso da forma presidenta (33\% e 100\%, respectivamente). Parlamentares do PC do B e do PT, únicos partidos com $100 \%$ de votos contrários ao impeachment, apresentaram também frequências superiores de emprego da variante presidenta (respectivamente, 57\% e 92\%).

Os resultados até aqui apresentados denotam que o emprego das variantes no contexto investigado sofre influência direta da posição político-ideológica do parlamentar. Ainda que tenha havido dificuldade na determinação dos partidos contrários e favoráveis ao governo, por conta da volatilidade das alianças firmadas ao longo de todo o processo, a relação entre os grupos voto no processo e partido político permite apontar com relativa assertividade as diferentes posições políticas no 
senado. Os/As parlamentares do bloco composto por PP, PSDB, PSD, DEM, PSB, PPS, PR, PTB, PSC, PV, S/P, REDE, em sua maioria, no momento do processo de impeachment, pertenceriam ao bloco de oposição ao governo, enquanto PT e PC do B, no outro polo, seriam partidos da base governamental. PDT e PMDB apresentariam maior equilíbrio entre parlamentares de oposição e situação.

Essas diferentes ideologias políticas interferem diretamente no emprego das variantes presidente/presidenta, por ser conhecido o posicionamento de Dilma Rousseff, dos representantes do governo e de seu partido em relação à preferência pela forma específica do gênero feminino. ${ }^{19}$

Na sequência, apresenta-se o terceiro grupo de fatores selecionado pelo programa estatístico GOLDVARB X, posição explícita em tribuna diante do processo.

\subsection{Posição em tribuna}

O grupo de fatores posição em tribuna considera a menção explícita do/a senador/a aos vocábulos “impeachment" (ou “afastamento") e "golpe". A hipótese sobre a atuação desse grupo diante da alternância lexical se deu devido à grande discussão que antecedeu o processo em diversas redes sociais. A expectativa era de que senadores/as que explicitamente considerassem o processo como "golpe" tendessem a empregar mais a forma presidenta; enquanto senadores/as que, em tribuna, se referissem ao processo como "impeachment" ou "afastamento" tenderiam mais ao emprego da forma presidente. Seguem, na tabela 5, os resultados para esse grupo de fatores:

\footnotetext{
${ }^{19}$ Merece registro o pronunciamento do senador Ronaldo Caiado, do DEM de Goiás, que, ao fazer a leitura de documento do ex-ministro Jaques Wagner em que constava "Quem banca é a presidenta...", substituiu a forma presidenta por presidente.
} 
TABELA 5 - Atuação do grupo de fatores posição em tribuna na alternância presidente/presidenta

\begin{tabular}{c|c|c|c}
\hline Variantes & Posição em tribuna & $\begin{array}{c}\% / \mathbf{n}^{\mathbf{0}} \mathbf{d e} \\
\text { ocorrências }\end{array}$ & Peso relativo \\
\hline \multirow{2}{*}{ Presidente } & impeachment ou afastamento & $92,7 \%(51 / 55)$ & $\mathbf{0 , 7 7 0}$ \\
\cline { 2 - 4 } & golpe & $17,2 \%(11 / 53)$ & 0,262 \\
\hline \multirow{2}{*}{ Presidenta } & impeachment ou afastamento & $7,3 \%(4 / 55)$ & 0,230 \\
\cline { 2 - 4 } & golpe & $82,8 \%(53 / 64)$ & $\mathbf{0 , 7 3 8}$ \\
\hline
\end{tabular}

Fonte: Elaborada pelos autores.

Os resultados confirmam totalmente as expectativas, haja vista os/as senadores/as que mencionaram os termos "impeachment" ou "afastamento" terem apresentado também alta frequência de emprego da forma presidente $(92,7 \%)$ e um peso relativo que mostra que o grupo tende ao emprego da forma conservadora $(0,770)$. Por outro lado, os/as senadores/as que se referiram explicitamente ao processo como "golpe" tenderam fortemente ao emprego de presidenta (frequência de $82,8 \%$ e peso relativo de 0,738 para uso dessa forma).

A validade da consideração desse grupo pode ser confirmada pela polarização entre os dois grupos, os que consideram o processo "golpe" e os que o consideram "impeachment/afastamento". No grupo anterior, que considerava o voto no processo, ainda que tenha havido diferença considerável entre os que votaram contra e a favor, a frequência de emprego da forma presidenta pelos que votaram sim, ainda que alta, foi menor, $65,1 \%$, contra $82,8 \%$ dos que consideraram o processo "golpe". Cabe relembrar que, para o grupo voto no processo, foram considerados todos os 48 parlamentares que fizeram uso da tribuna e, para o grupo posicionamento explícito sobre o processo, apenas os/as que mencionaram os termos "impeachment/ afastamento" ou "golpe". Passemos a tratar do último grupo de fatores selecionado, sexo.

\subsection{Sexo}

Para o grupo de fatores sexo, consideramos, entre os 48 parlamentares que fizeram uso da tribuna, 38 homens e 10 mulheres. A hipótese presente em estudos sociolinguísticos de diferentes fenômenos do português brasileiro mostra certa tendência de as mulheres empregarem com maior frequência a forma inovadora, desde que essa forma não seja 
estigmatizada, o que demonstra maior sensibilidade de representantes do sexo feminino em relação ao significado social das variantes linguísticas (FISHER, 1958; LABOV, 1990; PAIVA, 2015, entre outros).

É importante considerar, entretanto, a natureza específica da amostra analisada nesta pesquisa e, além disso, outros grupos de fatores, como os já apresentados, que poderiam atuar junto do grupo de fatores sexo. Reitera-se o fato de o fenômeno, e desse grupo de fatores em especial, estar fortemente ligado à identidade de gênero no discurso, já que as formas lexicais apresentam diferentes significações sociais, apesar de se alternarem nas mesmas funções. Seguem os resultados para esse grupo.

TABELA 6 - Atuação do grupo de fatores sexo na alternância presidente/presidenta

\begin{tabular}{c|c|c|c}
\hline Variantes & Sexo & $\begin{array}{c}\% / \mathbf{n}^{\mathbf{0}} \mathbf{d e} \\
\text { ocorrências }\end{array}$ & Peso relativo \\
\hline \multirow{2}{*}{ Presidente } & Masculino & $70,9 \%(122 / 172)$ & $\mathbf{0 , 5 8 7}$ \\
\cline { 2 - 4 } & Feminino & $38,3 \%(23 / 60)$ & 0,366 \\
\hline \multirow{2}{*}{ Presidenta } & Masculino & $29,1 \%(50 / 172)$ & 0,413 \\
\cline { 2 - 4 } & Feminino & $61,7 \%(37 / 60)$ & $\mathbf{0 , 6 3 4}$ \\
\hline
\end{tabular}

Fonte: Elaborada pelos autores.

Os resultados mostram maior tendência de emprego da forma presidente por parte dos senadores, com 70,9\% de frequência e peso relativo de 0,587. As senadoras, por outro lado, tenderam a empregar mais em seus discursos a forma presidenta, apresentando um percentual de $61,7 \%$ e peso relativo de 0,634 para uso dessa forma.

Por meio da observação dos resultados para o sexo e, considerando a premissa de que as mulheres são mais sensíveis ao significado social das variantes linguísticas, poderíamos concluir que a forma inovadora presidenta, por ser a mais empregada pelas mulheres, não seria estigmatizada. Entretanto, o contexto particular de investigação, com falta de equilíbrio entre os fatores sociais (como já demonstrado) sugere algumas ponderações e a consideração da relação deste com outros grupos de fatores. Como já mencionado, é pertinente também a consideração da especificidade da alternância, que comprova, na preferência pela forma presidenta, a defesa da ideologia de gênero. No quadro que segue, 
apresentamos a relação entre o sexo dos/as senadores/as e o voto no processo de impeachment.

QUADRO 2 - Relação entre o sexo e o voto no processo de impeachment

\begin{tabular}{|c|c|c|}
\hline Voto no processo & $\begin{array}{c}\mathbf{N}^{0} \text { de Senadores / } \\
\text { percentual }\end{array}$ & $\begin{array}{c}\mathbf{N}^{0} \text { de Senadoras / } \\
\text { Percentual }\end{array}$ \\
\hline Sim & $26 / 69 \%$ & $3 / 30 \%$ \\
\hline Não & $12 / 31 \%$ & $7 / 70 \%$ \\
\hline Total & $38 / 100 \%$ & $10 / 100 \%$ \\
\hline
\end{tabular}

Fonte: Elaborado pelos autores.

Entre os senadores, quase $70 \%$ foram favoráveis ao processo de impeachment (69\%) e, entre as senadoras, por outro lado, $70 \%$ foram contrárias ao processo. Há, dessa forma, falta de equilíbrio entre o voto de homens e mulheres no processo, e o resultado para o grupo de fatores sexo estaria sendo condicionado pelo posicionamento político-ideológico de cada um/a dos/as senadores/as da República. A confirmação dessa hipótese pode ser obtida com o cruzamento do grupo de fatores voto no processo e sexo, apresentado na sequência.

TABELA 7 - Cruzamento entre os grupos sexo e voto no processo de impeachment

\begin{tabular}{c|c|c|c}
\hline \multirow{2}{*}{ Voto } & \multirow{2}{*}{ Sexo } & \multicolumn{2}{|c}{ Variantes } \\
\cline { 2 - 4 } & & Presidente & Presidenta \\
\hline \multirow{2}{*}{ Sim } & Masculino & $97 \%(92 / 95)$ & $3 \%(3 / 95)$ \\
\cline { 2 - 4 } & Feminino & $100 \%(8 / 8)$ & $0 \%(0 / 8)$ \\
\hline \multirow{2}{*}{ Não } & Masculino & $39 \%(30 / 77)$ & $61 \%(47 / 77)$ \\
\cline { 2 - 4 } & Feminino & $29 \%(15 / 52)$ & $71 \%(37 / 52)$ \\
\hline
\end{tabular}

Fonte: Elaborada pelos autores.

Os resultados evidenciam comportamentos distintos entre os/as parlamentares pró e contra o impeachment, pois, entre os/as favoráveis ao processo, há a opção categórica ou quase categórica pelo emprego de presidente, independentemente do sexo. Já entre os/as parlamentares que votaram contra o impeachment, houve diferença no comportamento masculino e feminino, com maior tendência desse último grupo ao emprego da forma inovadora presidenta. 
Assim, entre os parlamentares contrários ao impeachment, é possível verificar diferença no comportamento masculino e feminino, com maior frequência de emprego da forma presidenta (inovadora e específica de referente do sexo feminino) pelas mulheres. Esse comportamento revela, para além da hipótese clássica, que defende maior sensibilidade por parte de representantes do sexo feminino em relação ao status social das variantes linguísticas, maior sensibilidade das mulheres também na determinação e no reconhecimento da identidade de gênero no discurso.

\section{Considerações finais}

Os resultados desta pesquisa confirmaram que a alternância das formas presidente e presidenta é influenciada, predominantemente, por fatores extralinguísticos ligados à ideologia política dos/das parlamentares, haja vista o partido político, o voto no processo e o posicionamento em tribuna terem sido os três primeiros fatores selecionados pelo programa estatístico GOLDVARB X. Além da ideologia político-partidária, foi possível constatar também a influência do grupo de fatores sexo no fenômeno variável.

Pela observação específica do grupo de fatores partido político, foi possível verificar um bloco de partidos com comportamento semelhante (PP, PSDB, PSD, DEM, PSB, PPS, PR, PTB, PSC, PV, Sem Partido e REDE), tendendo ao emprego semicategórico da forma presidente. Os representantes do PMDB e do PDT, apesar de usarem com alta frequência a forma presidente, destacam-se do bloco anterior, pois também empregaram a forma presidenta $(16,7 \%$ das ocorrências para o PMDB e 28,6\% para o PDT). Em comportamento inverso ao do primeiro bloco, parlamentares do PC do B e do PT revelaram maior tendência ao emprego da forma presidenta (destaque para o PT, que apresentou $92 \%$ de emprego da forma inovadora).

O grupo de fatores voto no processo revelou que o posicionamento do/a parlamentar em relação ao processo exerce influência na alternância lexical. Senadores/as favoráveis ao impeachment apresentaram maior tendência ao emprego da forma presidente do que senadores/as contrários ao processo.

A análise do grupo de fatores posição em tribuna, por considerar apenas os/as parlamentares que se posicionaram explicitamente na sessão em relação ao processo, revelou com maior clareza os polos de oposição da variação e a relação entre o posicionamento político-ideológico e sua 
manifestação no discurso, revelando a preferência dos senadores que votaram sim pela forma presidente e dos que votaram não pela forma presidenta.

O grupo sexo, apesar de exigir cautela em sua análise, devido à falta de equilíbrio da amostra, comprovou a maior sensibilidade feminina na determinação e reconhecimento da identidade de gênero no discurso, com as mulheres tendendo mais ao emprego da forma presidenta do que os homens.

Embora o contexto de investigação desta pesquisa tenha sido restrito, os resultados possibilitam uma visão mais ampla do fenômeno de alternância lexical entre as formas presidente e presidenta, visto que, dentro e fora do Senado Federal, a discussão sobre o emprego de uma ou outra formas quase sempre extrapola os rótulos de padrão ou não padrão, prestígio ou estigma, culto ou popular. Além disso, o julgamento pessoal, social e político dos senadores em relação ao referente-alvo da forma lexical está em jogo e tem maior peso nesse contexto específico de variação. Há, notadamente, uma polarização político-ideológica, e o falante determina o polo que irá ocupar no momento em que faz a opção por uma das formas lexicais.

\section{Referências}

BECHARA, E. Moderna gramática portuguesa. 37. ed. Rio de Janeiro: Lucerna, 2001.

BENVENISTE, E. Estrutura das relações de pessoa no verbo. Problemas de Linguística Geral I. 3. ed. São Paulo: Pontes, 1991.

BROWN, P.; LEVINSON, S. Politeness: Some universals in language usage. Cambridge: Cambridge University Press, 1987.

CAMACHO, R. G. Uma reflexão crítica sobre a teoria sociolinguística. DELTA, v. 26, n.1, p.141-162, 2010. Disponível em: <http://www. scielo.br/scielo.php?pid=S0102-44502010000100006\&script $=$ sci abstract\&tlng=pt $>$. Acesso em: 24 nov. 2016.

CÂMARA JR., J. M. Princípios de linguística geral. 4. ed. Rio de Janeiro: Livraria Acadêmica, 1970.

CÂMARA JR., J. M. Estrutura da Língua Portuguesa. 15. ed. Petrópolis: Vozes, 1984. 
COURTINE, J. J. Definition d'orientations théoriques et construction de procedures em analyse du discours. Philosophiques, Société de Philosophie du Québec, v. 9, n. 2, p. 239-264, 1982. Doi: 10.7202/203194ar.

ECKERT, P. Goes to the City: Exploring the Expressive Use of Variantion. In: GUY, G.; FEAGIN, C.; SCHIFFRIN, D.; BAUGH, J. (Ed.). Towards a Social Science of Language. Papers in Honor of Willian Labov. Amsterdam/Philadelphia: John Benjamins Publishing Company, 1996. v. 1, p. 47-68. Doi: https://doi.org/10.1075/cilt.127.06eck.

FERREIRA, A. B. H. Novo Dicionário Aurélio da Língua Portuguesa. 4. ed. Curitiba: Editora Positivo, 2009.

FERREIRA, M. B.; SILVA, R. C. M. Sobre a palavra presidenta. Presidenta existe na língua portuguesa desde 1972. Último segundo Educação, São Paulo, 15 set. 2011. Disponível em: < http://ultimosegundo. ig.com.br/educacao/presidenta-existe-na-lingua-portuguesa-desde-1872/ n1597210547562.html>. Acesso em: 11 out. 2016.

FISHER, J. L. Social influences on the choice of a linguistic variant. Word, Taylor \& Francis Online, v. 14, p. 47-56, 1958.

FREITAG, R. M. K. Problemas teórico-metodológicos para o estudo da variação linguística nos níveis gramaticais mais altos. Matraga, Rio de Janeiro, v. 16, n. 24, jan./jun. 2009.

GIVÓN, T. Markeness in Grammar: distributional, communicative and cognitive correlates of syntactic structure. Technical Report, University of Oregon, v. 90, n. 8, 1990.

LABOV. W. Sociolinguistic Patterns. Philadelfia: University of Pensylvania Press, 1972.

LABOV. W. Where does the linguistic stop? A response to Beatriz Lavandera. Working Papers Sociolinguistics, Austin, Texas, Southwest Educational Development Laboratory, n. 44, 1978.

LABOV. W. The intersection of sex and social class in the course of linguist change. Language Variation and Change, Cambridge University Press, n. 2, p. 205-254, 1990.

LABOV. W. Principles of linguistic change: internal factores. Oxford: Blackwell, 1994. 
LABOV. W. Padrões sociolinguísticos. Tradução de Marcos Bagno, M. Marta P. Scherre e Cristiane R. Cardoso. São Paulo: Parábola, 2008.

LAVANDERA, B. R. Where does the sociolinguistic stop? Language Society, London, v. 7, p. 171-182, 1978.

MOLLICA, M. C.; BRAGA, M. L. (Org.). Introdução à sociolinguística: o tratamento da variação. 4. ed. São Paulo: Contexto, 2015.

ORLANDI, E. P. A sociolinguística, a teoria da enunciação e a análise do discurso. In: . A linguagem e seu funcionamento. 2. ed. Campinas: Pontes, 1987.

PAIVA, M. da C.; SCHERRE, M. M. P. Retrospectiva sociolinguística: contribuições do PEUL. D.E.L.T.A., PUC-SP, v. 15, n. especial, p. 201232, 1999.

PAIVA, M. da. C. A variável gênero/sexo. In: MOLLICA, M. C.; BRAGA, M. L. (Org.). Introdução à sociolinguística: o tratamento da variação. 4. ed. São Paulo: Contexto, 2015.

PÊCHEUX, M. Semântica e discurso: uma crítica à afirmação do óbvio. Tradução de Eni P. Orlandi et al. Campinas: Editora da Unicamp, 1998.

PERINI, M. A. Gramática do Português Brasileiro. São Paulo: Parábola, 2010.

SALLES, L. M. S. Quando os constituintes à esquerda como estratégia de venda são silenciados: análise e tratamento político da sintaxe da corp(oralidade). 2015. 192f. Tese (Doutorado em Linguística) Universidade Federal do Rio de Janeiro, Rio de Janeiro, 2015.

SANKOFF, David.; TAGLIAMONTE, Sali A.; SMITH, Elen. Goldvarb X - a multivariate analysis application. Toronto: Department of Linguistics; Ottawa: Department of Mathematics, 2005. Disponível em: $<$ http:// individual.utoronto.ca/tagliamonte/goldvarb.html>. Acesso em: $15 \mathrm{fev}$. 2017.

SCHERRE, M. M. P. Paralelismo linguístico. Revista de Estudos da Linguagem, Belo Horizonte, UFMG, v. 7, n. 2, p. 29-59, 1998. Doi: http:// dx.doi.org/10.17851/2237-2083.7.2.29-59.

SOUZA-E-SILVA, M. C. P. de; KOCH, I. V. Linguística aplicada ao português: morfologia. 18. ed. São Paulo: Cortez, 2011. 
VOCABULÁRIO ORTOGRÁFICO DA LÍNGUA PORTUGUESA. Academia Brasileira de Letras. 5. ed. São Paulo: Global, 2009.

VOTRE, S. J. Relevância da variável escolaridade. In: MOLLICA, M. C.; BRAGA, M. L. (Org.). Introdução à sociolinguística: o tratamento da variação. 4. ed. São Paulo: Contexto, 2015.

WEINER, J.; LABOV, W. Constraints on the agentless passive. Journal of Linguistics, Cambridge, n. 19, p. 29-58, 1977.

WEINREICH, U.; LABOV, W.; HERZOG, M. Fundamentos empiricos para uma teoria da mudança linguística. São Paulo: Parábola Editorial, 2006. 